\title{
Problem-posing triggers or where do mathematics competition problems come from?
}

\section{Igor' Kontorovich ${ }^{1}$ (D)}

Published online: 11 September 2020

(C) The Author(s) 2020

\begin{abstract}
Spurred by Kilpatrick's (1987) "Where do good problems come from?", this study explores problem-posing triggers of experienced problem posers for mathematics competitions. Triggers are conceived as instances of noticing, where an impulse draws a poser's attention and 'triggers off" a mathematical re-action, one of the outcomes of which is a creation of a problem that gets accepted to some mathematics competition. The data were collected from 26 problem posers residing in nine countries, and who had experience in creating problems for national, regional, and international competitions. Three types of triggers emerged from the analysis: (i) Instances where the participants extracted mathematical phenomena from activities that are replete with modern elementary mathematics. These triggers were described in emotionally loaded terms that resonated with appreciation, surprise, challenge, and feeling of innovation. (ii) Cases where the participants abstracted mathematical phenomena from common everyday-life tasks in which mathematical optimization was beneficial. These situations emphasized participants' desire to compensate for self-disappointment with an initially made decision and the value of finding a better alternative. (iii) Situations where the participants were asked to pose a problem 'here and now'. The posers were unanimous in their dislike of such situations. They elaborated on how difficult it is to pose 'here and now' and highlighted the low quality of the resulting problems. The findings are situated in the body of knowledge on expert problem posing and educational literature on school students and teachers.
\end{abstract}

Keywords Problem-posing triggers · Discipline of noticing - Expert problem posing · Mathematics competitions

Igor' Kontorovich

i.kontorovich@auckland.ac.nz

1 The University of Auckland, Auckland, New Zealand 


\section{Introduction}

Problem posing has been drawing the keen attention of the mathematics education community for almost four decades (e.g., Brown \& Walter, 1983; Ellerton, 1986; Walter, 1978). In his seminal paper entitled "Problem formulating: Where do good problems come from?", Kilpatrick (1987) presented an ambitious agenda for providing opportunities for school students to create their own mathematical problems. Since then, the potential of problem posing for promoting problem solving, advanced mathematical thinking, conceptual understanding, creativity, and positive attitudes towards mathematics has been extensively explored (see Cai, Hwang, Jiang, \& Silber, 2015 and Singer, Ellerton, \& Cai, 2013 for comprehensive reviews). However, Singer et al. (2013) note that despite the accumulated body of valuable insights on the development of problem posing in students and teachers (who are usually novices to this activity), the issue of insufficient quality of their problems remains contentious and requires further investigation. In a similar vein, Cai et al. (2015) invite future studies to explore why "students pose nonmathematical, trivial, or otherwise suboptimal problems or statements." (p. 9) Accordingly, a revised version of Kilpatrick's question can be, "How can novices be supported to formulate good problems?"

At least two general research approaches come to mind with respect to the revised question. In the first one, research examines the impact of various instructional elements on the quality of the posed problems (e.g., see Crespo \& Sinclair, 2008 for a design of a problem-posing setting; Kontorovich, Koichu, Leikin, \& Berman, 2012 for learners' considerations of what is an appropriate response in a problem-posing situation). The study in hand draws on another approach, the one arguing that having an accurate understanding of how experts create mathematical problems can and should inform the goals and methods of problem-posing instruction. This approach is appreciably less common in mathematics education, which is somewhat peculiar given that mathematicians were the first to recognize the importance of problem posing in their practice (e.g., Einstein \& Infeld, 1938).

There are at least two reasons for the educational problem-posing community to be interested in expert problem posers. First, it is a proven practice in the mathematics education community to utilize research on experts as a source of insight for advancing novices (e.g., see Schoenfeld, 1992 for problem solving, Wilkerson-Jerde \& Wilensky, 2011 for learning mathematics; Liljedahl, 2009 for discovering new mathematical phenomena). By analogy, research on where experts' problems come from may also be profitable for instructional problem-posing purposes. Second, it is accepted by many mathematics educators that, to some extent, learners' mathematical doings should be analogous to how these doings unfold in professional mathematics communities (e.g., Schoenfeld, 1992). In the words of Stylianou (2002), "if indeed we choose to focus [instruction] on professional mathematical practice, then it is crucial to have a thorough understanding of this practice" (p. 304). Put another way, if the mathematics education community is interested in students and teachers experiencing expertlike problem posing and creating 'good' problems as part of it, research is needed on "where experts' problems come from".

Having no intention to come up with a blanket approach to who problem-posing experts are, I argue that people systematically creating problems for high-level mathematics competitions (MCs) may be considered as such. Indeed, MCs are often reputed as treasures of "elegant," "intriguing," and "surprising" problems that reach the students after thorough discussions in MC committees (e.g., Koichu \& Andžāns, 2009; Sharigin, 1991; Wieschenberg, 
1990). Then, it seems reasonable to propose that experienced problem posers and their MC problems are suitable nominees for exploring "where experts' problems come from."

To raise the relevance of this study, my operationalization of Kilpatrick's "where from" is in accord with some common trends in educational problem-posing research. More often than not, students and teachers' problem posing is triggered by tasks explicitly asking them to come up with a problem or a set of problems (e.g., Ellerton, 1986; Koichu \& Kontorovich, 2013). A considerable research effort has been invested in designing problem-posing tasks and exploring their implications (e.g., Crespo \& Sinclair, 2008; Singer \& Voica, 2013). Sometimes these tasks have been considered through a broader lens of problem-posing situations (Kontorovich et al., 2012; Stoyanova, 1998). In this way, research seems to agree that the initial situations from "where problems come from" have a significant impact on the quality of the resulting problems.

As a rule, experienced problem posers for MCs (EPPMCs) are not given tasks, and they are not put in problem-posing situations in the sense that these terms are used in the mathematics education community (e.g., Cai \& Hwang, in press). Accordingly, this study is concerned with what can draw EPPMCs' attention and trigger processes eventually leading them to problems of the competition quality.

\section{Background}

This section presents the study's conception of problem posing, positions the MCs movement as a community of practice, and reviews findings on expert problem posing.

\subsection{Conceptions of problem posing}

Following Silver (2013), both Cai and Hwang (in press) and English (in press) draw attention to fundamental conceptions in problem posing research. On the one hand, what can be more straightforward than associating problem posing with "the process of formulating and expressing a problem within the domain of mathematics" (Cai \& Hwang, in press, p. 2)? On the other hand, Silver (2013) calls for making "sharper distinctions among several manifestations of mathematical problem posing as a phenomenon" (p. 159). Drawing on Brousseau (1997), Koichu (in press) distinguishes between a-didactical and didactical problem posing. In the former, problem posing is an implicit objective of some other activity, such as investigating (e.g., Crespo \& Sinclair, 2008; Leikin \& Grossman, 2013) or problem solving (e.g., Koichu, in press; Singer \& Voica, 2013). When manifested didactically, problem posing constitutes "an isolated activity where it becomes an end in itself" (English, in press, p. 3).

Being interested in "where the problems of EPPMCs come from," this study begs for a conception that is capable of accommodating a wide range of problem-posing manifestations. A union of didactical and a-didactical approaches might satisfy this purpose. An even more inclusive conception can be developed based on Klinshtern, Koichu, and Berman (2015) who come from a teacher-centered perspective and associate problem posing with

an accomplishment that consists of constructing a problem that satisfies the following three conditions: (1) it somehow differs from the problems that appear in the resources 
available to the teacher; (2) it has not been approached by the students; and (3) it can be used in order to fulfil teaching needs that could be difficult to fulfil. (p. 463)

Klinshtern et al.'s (2015) proposal is notably inclusive since it does not specify what problem posing looks like, and it treats the construction of a problem as a posterior marker of problem posing. An accomplishment, in turn, is associated with a problem that satisfies quality criteria that are derived from a poser's professional needs and shaped by the norms of the relevant professional community. Along the same lines, for the purposes of this study, I associate problem posing with instances where an experienced problem poser constructed a problem that has been accepted to some MC. The problem's acceptance marks the poser's accomplishment to fulfill not only their personal criteria of quality but also those that are shared by the MCs movement as a community of practice.

\subsection{The Mathematics competitions movement as a community of practice}

Wenger and Snyder (2000) associate communities of practice with groups of people who are bound together by shared expertise and passion for a joint enterprise. Such groups are characterizable through: their domain, which constitutes a shared identity and interest to which the participants are committed; the community whose members engage in joint activities and discussions through which they learn, create, and share knowledge; and practice, which is a shared repertoire of resources that the participants of the community produce (Wenger-Trayner \& Wenger-Trayner, 2015). I argue that communities emerging around particular MCs and the $\mathrm{MC}$ movement as a whole may be construed as a community of practice. I use this construct to review those features of the MCs movement that are necessary to make sense of the findings in Section 5.

The domain of the MCs movement can be associated with modern elementary mathematics, which Koichu and Andžāns (2009) define as a union of (i) elementary methods that are recognized by the mathematics community as not depending on any specific branch of modern mathematics, but broadly used in many branches (e.g., induction, considerations of symmetry); and (ii) problems that can be solved by means of these methods. Practically speaking, the problems in this domain often revolve around topics that are typical to secondary school mathematics (specifically, number theory, algebra, trigonometry, combinatorics, and plane and solid geometry) but their solutions are more demanding than those prescribed by standard curricula (e.g., Wieschenberg, 1990).

The term "MCs" is rather misleading as it draws attention only to a small portion of activities characteristic to the MCs movement. Since their conception, MCs have been accompanied by a wide range of endeavors and initiatives intended for students and teachers who are interested in accessible mathematics that goes beyond standard school curricula (see Koichu \& Andžāns, 2009 for a brief history of the MC movement). Typical examples of such endeavors and initiatives include publications of special journals and books, and organization of various out-of-school workshops, circles, and summer camps. These satellite activities are practically the ones that turn MCs - occasional gatherings where adolescent participants solve problems posed by adult participants - into vivid communities where students and adults sustain "enough mutual engagement in pursuing an enterprise together to share some significant learning." (Wenger, 1998, p. 86). Such productive maintenance of the movement requires its participants to fill a wide range of roles. Some of them are assigned formally, and they are intended for clearly defined periods of time, such as organizing an annual MC or a training 
camp. Other roles are filled thanks to the alignment between the movement's needs and the participants' interest to contribute, for instance, through posing problems (Kontorovich, 2015).

The practice of the MCs communities is broad, diverse, and easily accessible nowadays. While the accessibility of resources supports learning and knowledge sharing, it also poses some non-trivial challenges for problem posers. MC problems have been often held to the highest standards of mathematical taste, beauty, challenge, and creativity (e.g., Koichu \& Andžāns, 2009; Sharigin, 1991; Wieschenberg, 1990). The problems are expected to be novel and challenging for competing students, when posers can never be fully aware about the mathematical background of competitors who decide to participate in a specific MC each time. The domain of MCs sets its boundaries for problem posers as well. Andžāns, Bērziña, and Bonka (2006) explored the mathematical content of Olympiad problems worldwide and produced a 50-page classification of mathematical ideas and problem-solving methods that the community expects the competing students to know. These ideas and methods can be associated with an unofficial curriculum shared by many MCs.

\subsection{Expert problem posing}

Avital and Libeskind (1978), Brown and Walter (1983), Kilpatrick (1987), Sharigin (1991) and Walter (1978) - this is a more or less exhaustive list of publications that address the question of "where do EPPs get their problems from?" While being self-reflective (see van Someren, Barnard, \& Sandberg, 1994 for limitations of this method of enquiry), these publications come from problem posers who are highly valued in their respective communities and for whom problem posing constitutes a fundamental part of their professional practice.

With respect to the abovementioned question, Kilpatrick (1987) elaborates on the processes one goes through when solving a problem given to them by others, on typical problem-posing stages, and on real-life situations that can be modeled. Sharigin (1991) points out that new problems usually come from other problems the poser is familiar with, and he presents a list of six techniques that can be used for creating new problems (specifically, reformulating, chaining, considering special cases, generalizing, varying the givens and inquiry). Avital and Libeskind (1978) illustrate that some of these techniques can be applied to advanced mathematics to create problems for secondary students.

The notion of problem source appears in several experts' self-reflections, but none of them explicate the meaning behind it. Indeed, the previous paragraph illustrates that the notion is used broadly and differently by different posers. In fact, the entities that experts gather under the ontological umbrella of a source are so diverse that one may get an impression that anything could give rise to a new mathematical problem (see Walter, 1978 who literally argues this point). However, there are empirical reasons to doubt this impression. In Kontorovich and Koichu (2012, 2016), we provided one EPPMC, Leo, with a particular mathematical situation and asked him to use it as a source to pose problems. Leo did not engage with the offered source and driven by the feeling of innovation resorted to his repertoire of nesting ideas. With the "feeling of innovation", we explained Leo's recurrent reflection on whether his newly posed problem was substantially different for him from those he was familiar with. The construct of nesting ideas was introduced to capture the structure of Leo's pool of familiar problems as being divided into classes, when problems in each class were connected through a special idea that brought them together ("a nest"). Furthermore, such ideas were open for manipulations allowing Leo to "lay" new problems when he needed them. The case study of Leo 
can be considered as a proof of concept showing that affective structures can play a major role in expert problem posing and that an advanced theoretical apparatus is needed to take this role into account.

\section{Theoretical framing}

The theoretical framework of this study is assembled from Mason's (2002) Discipline of noticing (Section 3.1). The framework is used in Section 3.2 to formulate the aim of the study.

\subsection{Discipline of noticing}

Mason (2002) maintains that "at the heart of all practice lies noticing: noticing an opportunity to act appropriately." (p. 1) Accordingly, he positions the Discipline of noticing as a collection of practices targeted at transitioning noticing that takes place on its own, i.e., without any particular effort within one's field of practice, to become more systematical, disciplined, nuanced, and consequently more open to change. I draw on those components of the discipline that pertain to capturing, systematizing, and sensemaking of expert noticing.

Two central premises shape Mason's (2002) discipline. The first one conceives attention as a complicated human mechanism, in which noticing is responsible for distinguishing some things from their surroundings and getting them through to the level of awareness. Mason associates such a distinction with a registration of some change in perceptual apparatus, a change that could be physical, emotional, or cognitive. The second premise posits that it is impossible to act on something without this something being noticed (i.e., to re-act).

Mason (2002) maintains that "[t]he mark of an expert is that they are sensitized to notice things which novices overlook. They have finer discernment" (p. 33). He links this discernment to being present and sensitive in the moment, having a reason to act, and possessing a repertoire of appropriate re-actions. Yet, Mason argues that professional habits come hand in hand with automaticities that are necessary to cope with a myriad of choices that need to be made even in a typical situation. On the level of noticing, the described trap of habit is realized in Mason (2002) positing,

"[...] you can only notice what you are already sensitized to, though this sensitivity may

shift over time. ... [Y] our observations are theory-laden: you can only see aspects which

you are already disposed or primed to see.” (p. 38)

This could be understood that noticing often "happens to a person" rather than something that can be planned in advance. Accordingly, noticing is inseparable from some external impulses that draw one's attention. Which impulses trigger attention and which impulses pass by? Mason suggests that an impulse can cause a disturbance or resonance through striking a chord with past experiences. In his words, "Not a tidal wave, but a ripple sufficiently great to be distinguishable on the choppy surface which is my experience" (p. 68). For instance, a noticed impulse can help in making sense of something, in fitting, or contradicting something that is held as true.

The discipline suggests that the essence of noticing is being awake to situations and being mindful rather than mindless (Mason, 2002). Metaphorically speaking, Mason 
associates noticing with an inner monitor who witnesses a situation and alerts the acting self to act differently. An echoing approach can be found in Schön's (1983) "reflection-in-action," which refers to experts' tendency to act intuitively and spontaneously while "thinking on their feet". This often comes as a re-action to the situations of uncertainty and uniqueness that diverge from the usual practice. It is important to highlight that Mason (2002) suggests accessing past instances of noticing through a methodical recall of events as they appear to the person's eye, and his discipline is not troubled by the match between this appearance and some "real" occurrence of events.

\subsection{Aim}

The central construct of this study is problem-posing triggers. In line with Mason (2002), I associate triggers with instances of noticing, where an impulse draws a person's attention and "triggers off" processes eventually leading to the construction of a problem. The word "trigger" comes to highlight that noticing can be rapid, non-conscious, and appeal to an affect-emotional domain (Mason, 2008). In accord with Section 2.1, the adjective "problem-posing" is ascribed to "a trigger" in a posterior sense that evidences the productivity of the encounter between a person and an impulse that "happened to each other," rather than "problem posing" as an explicit goal that a person sets themselves on the encounter with the impulse. This post-factum approach allows not to ascribe an a priori or in-the-moment objective of posing a problem to the person. In a similar vein, I refer to this study's participants as "EPPMCs" to recognize their systematic problem-posing accomplishments while acknowledging that posing new problems might not be the only objective that they pursue in the MCs movement. In these terms, the aim of this study is to characterize problem-posing triggers from EPPMCs' perspectives with an eye to the impulses that they encounter and the resonance that these impulses entail.

\section{The study}

This study is conducted with an exploratory methodology, which Stebbins (2001) positions as a preferred approach when the phenomenon of interest has received little or no systematic study. Within this methodology, the focus is on the inductive generation of empirical generalizations. In this study, the generalizations emerge from 26 problem posers for national, regional, and international MCs, such as Baltic Way Mathematical Contests (http://www.math. olympiaadid.ut.ee/eng/html/?id=bw), Mathematical Kangaroo (http://www.mathkangaroo. org/mk/default.html), and Tournament of Towns (https://www.turgor.ru/en/index.php). At the time of data collection, the average problem-posing experience of the participants was 25 years and it ranged from 7 to 37 years. The participants resided in Australia $(n=1)$, Bulgaria $(n=1)$, Israel $(n=9)$, Latvia $(n=1)$, Lithuania $(n=1)$, Russian Federation $(n=7)$, Spain $(n=1)$, Sweden $(n=1)$, and the USA $(n=4)$. Seventeen of them hold doctoral degrees in mathematics and two in mathematics education; six participants had a master's in mathematics and one in mathematics education. Nineteen participants were staff members in universities and colleges, four were high-school teachers, and one was an engineer in a 
high-tech industry. Only two participants earned their living through their practice in the MCs movement.

Aiming at a theoretical and methodological coherence (Lerman, 2019), the construction of a data corpus and its further analysis were shaped by selected practices from Mason's (2002) Discipline of noticing. The discipline operates with written accounts-of some memorable incidents, when memorability is considered as a mark of personal importance, often because of some emotional or intellectual commitment to the incident. In writing, the discipline advocates for using accounts-of that describe "as objectively as possible by minimizing emotive terms, evaluation, judgments and explanation" (Mason, 2002, p. 40). Mason claims that such accounts pave the way to identifying a general phenomenon that can be investigated systematically.

To access the problem-posing triggers of the participants, they were first asked to select and email some of their past MC problems, the stories of the creation of which they remembered in detail. This request had a preparatory aim of assisting the participants with reentering their past triggering experiences and it also provided me with an opportunity to prepare relevant questions to the forthcoming interviews. The participants shared between 5 and 11 problems at this step.

The next step consisted of individual semi-structured interviews, where I asked the participants to describe, in as much detail as possible, the stories behind the creation of their selected problems. Through such probing questions as "How did you get the idea for this problem?", "Why did you decide to develop this idea in that direction?", and "Why did you choose to share this particular problem?", I aimed at developing vivid impressions of the impulses that the participants noticed, making sense of disturbances that they entailed with an eye to the participants' affective experiences. Nine participants were interviewed face-to-face, and nine by phone and Skype. The interviews lasted between 60 and 90 minutes. An overall 25 hours of audio-taped interviews were collected in this step. Eight participants preferred to communicate in writing by filling in a questionnaire consisting of the central questions of the interview.

In the next step, I engaged in the construction of brief-but-vivid accounts-of incidents and experiences that preceded the participants creating their problems (cf. Mason, 2002, pp. 4649). Mason (2002) suggests that brevity is valuable to reduce cognitive load, when vividness enables re-entering the accounted experiences. To enhance the credibility of my accounts, a member check technique was employed (e.g., Lincoln \& Guba, 1985, p. 314) to provide the participants with the possibility to modify the drafts of their accounts and better align them with the recollections of their experiences. All the participants responded either with endorsing the constructed accounts or offering minor amendments. Overall, 99 accounts were produced at this step, each focusing on a single triggering experience.

The last step consisted of a thematic analysis, where the EPPMCs' accounts, interviews, and questionnaires were examined in a search for common threads (Mason, 2002). These threads were developed with the theoretical tools in Sections 3 with the aim of providing structure and coherence to the rich palette of the data corpus. One of the quickly emerged threads pertained to the nature of the triggering impulses that the participants encountered. Some impulses came in the form of explicit requests asking the participants to create problems with particular specifications, and this category was later developed into a trigger "Wishing to pose a problem "here and now"' (see Section 5.3). The nature of other impulses seemed less straightforward. The accounts in this second category told various problem-posing stories unfolding in different contexts (e.g., when reading MC literature, working on mathematical 
problems as part of their academic research, using a key to open a door, opening a tap to fill a bathtub). The motivation not to fraction the diversity of this category was spurred by the positive and somewhat similar affective coloring that the participants highlighted. This coloring offered a nice contrast to the accounts in the first category, which was expressed in exceptionally negative terms. Eventually, the second category was divided between accounts where the triggering impulse engendered in modern elementary mathematics (see Section 5.1) and those where the participants engaged in common everyday-life tasks that are not specific to the MC movement (see Section 5.2). An iterative application of a constant comparison technique (Glaser \& Straus, 1967) revealed that the accounts in these sub-categories differed in the activities where the participants encountered the triggering impulses and the nature of mathematical ideas that they extracted from these impulses.

\section{Findings}

This section presents three broad categories of triggers that emerged from the data analysis: extracting mathematical phenomena from modern elementary mathematics, abstracting mathematical phenomena from optimization-inviting tasks, and wishing to pose a problem "here and now". The triggers are illustrated with EPPMCs' accounts and excerpts from their questionnaires and interviews that have been selected due to their representativeness of broader categories. To protect the confidentiality of the participants, while acknowledging their authorship of opinions and ideas, I refer to them through their initials.

\subsection{Extracting mathematical phenomena from modern elementary mathematics}

The EPPMCs' participation in the MCs movement was not limited to a single role of problem posers. At different points in their careers, all of them led various extracurricular activities for school and university students (e.g., mathematical circles), contributed to campuses preparing students for specific MCs (e.g., International Mathematical Olympiad), and served on organizational MC committees. The fulfillment of these roles required the participants' engagement in a range of characteristic activities, such as keeping up-to-date with the MC literature, teaching relevant topics to students, and discussing, solving, and posing mathematical problems. These activities have been replete with modern elementary mathematics, the encounter with which frequently set the EPPMCs on the paths that led to the creation of new problems. Metaphorically speaking, these activities can be associated with a fertile ground where the EPPMCs harvested triggering mathematical impulses.

The full list of activities addressed by the participants is presented in Table 1, where the right column indicates the number of EPPMCs who pointed at their engagement in these

Table 1 Activities replete with elementary modern mathematics 
activities on a regular basis and offered at least one account of a problem that emerged from such an activity. Overall, each participant reported that they regularly engage in at least two activities from Table 1, when an engagement with the MC literature was common to all participants. The activity of "conducting scholarly research" emerged from the data that attested to periods when the EPPMCs were graduate students and from the accounts of those who pursue academic research in science, technology, engineering, or mathematics. For instance, the mathematician AK noted that his "Olympiad and competition problems are often by-products - high-quality by-products! - of the things that I do in math that has no connection to competitions." While not dealing with modern elementary mathematics per se, several mathematicians remarked that it is not unusual for them to notice when some piece of mathematics that they work on is also accessible with more elementary methods.

Each participant situated their MC experience within a few mathematical specializations. These specializations mostly overlapped with the content areas traditionally associated with MCs (see Section 2.2), when some participants framed their specializations in more focused terms, such as "mathematical inequalities". Only two participants described themselves as specializing in one content area, twenty positioned themselves in two areas, and the remaining four EPPMCs attested to their experience as being spread among three content areas. The participants reported that these specializations shape the literature that they engage with, the problems, on solving and posing of which they spend most of their time, and impulses that they tend to notice and seek. Furthermore, a specialization constitutes a key component of their problem-posing profile in a broader MC community, which enables it to make an efficient use of the EPPMCs' experience (see more on this point in Section 5.3).

Let me attend to two accounts illustrating EPPMCs' recollections of an experience of being triggered by some mathematical impulse. The accounts come from the data on VB and AZ correspondingly, both specializing in geometry. VB's account exemplifies a trigger coming from an EPPMC's engagement with the MC literature, when AZ's account demonstrates how triggering can be an EPPMC's participation in MC committees.

\section{Account 1: Learning a powerful theorem}

"Once I was browsing through a problem section in $\mathrm{Kvant}^{1}$ and found this one: 'In a convex quadrilateral $\mathrm{ABCD}$ an interior point $\mathrm{M}$ creates two isosceles triangles $\mathrm{AMB}$ and $\mathrm{CMD}$. The vertex angle $\mathrm{M}$ in these triangles is $120^{\circ}$. Prove that there exists a point $\mathrm{N}$, such that the triangles BNC and DNA are equilateral.' I embarked on the problem and it took me about a week to solve it. My solution was quite messy and complicated, and I was waiting for the next issue of Kvant where the author's solution would be published. I remember being convinced that it will be much simpler than mine.

I still remember how overwhelmed and even shocked I was when I saw the solution. It took them four lines, when my solution was five-page long! They used a tricky Charles theorem, to solve the problem. So, I opened the books and started reading about this theorem. Charles Theorem states that every displacement of a plane is a composition of a translation along a line and a rotation around that line. It made me think about things like displacement and possible

\footnotetext{
${ }^{1}$ First issued in Soviet Union in 1970, Kvant is a popular science magazine that continues to publish articles in physics and mathematics for school students and teachers. Translations of Kvant's selected articles to English can be found at https://www.nsta.org/publications/quantum.aspx.
} 
kinds of displacements. When I got all that, I came up with a whole set of problems based on this theorem."

\section{Account 2: Spotting a similarity between different problems}

"I participated in several Olympiad committees and paid attention to similar problems that I never thought about before. All of them focused on special triangles in which three of their special segments (i.e., medians, bisectors and heights) were equal. I've become interested but also slightly upset with myself for not considering this case beforehand. I also noticed that in all these problems, two segments were of the same kind, for instance, two heights and a median, or two bisectors and a height. It gave me an idea 'what will happen if a median equals to a bisector and to one of the heights in a triangle?"'

The above accounts illustrate two common threads that were characteristic to the trigger in the focus of this section. The first thread is focused on VB and AZ describing their feelings of being overwhelmed, shock, and disappointment, which illustrates a broader pattern where many accounts contained emotionally loaded descriptions of EPPMCs encounters with triggering mathematical impulses. These descriptions can be interpreted as evidence of an affective resonance that the EPPMCs experienced. In many cases, the accounts captured mixtures of emotions. Note how AZ recalls becoming "slightly upset" with himself but also "interested" in problems that he did not consider beforehand. The feelings of innovation, surprise, and appreciation can be read between the lines of VB's account.

Overall, the emotional richness of the described accounts may explain the remarkable level of details that some EPPMCs provided on incidents that took place years and sometimes even decades ago (see Account 1 for example). This is in accord with Mason (2002), who commented that "Incidents which stay in memory are usually ones in which we have considerable or intellectual commitment. They are 'important' to us for some reason." (p. 39) The analysis of the collected accounts allows suggesting that this commitment and importance often emerged from mathematical impulses that disturbed EPPMCs' mathematical knowledge base in some way. For instance, through challenging something that they knew or through illuminating aspects that they were unfamiliar with in their specializations.

The second thread is concerned with the mathematical phenomena that the EPPMCs discerned from the noticed impulses. Indeed, consider the ease with which VB identifies "a tricky Charles theorem" as a source that endowed Kvant's solution with all its qualities. Account 2 does not specify the problems that AZ encountered, but it explicates the essence of the similarity that he noticed among the "special triangles in which three of their special segments (i.e., medians, bisectors, and heights) were equal." I use "mathematical phenomenon" to refer to the EPPMCs' formulations of self-contained mathematical situations where a special relation among its components is shaped (or there was a reason for the EPPMCs to expect it to shape some other component). Additional examples of such phenomena included situations involving the triangle's orthocenter with all its properties and representing integers as sums of arithmetic sequences.

The formulations of the phenomena that the EPPMCs extracted drew attention to particular aspects and connections that, as one of the participants put it, "begged for a mathematical investigation". While not prescribing how these investigations should be carried out, for mathematically experienced people, like the EPPMCs, these formulations set up general courses for possible investigative actions. For instance, what would VB be expected to do to get himself familiar with a new theorem? Probably, to learn its 
concepts and proofs. AZ, in turn, engaged in the characterization of the "special triangles" through exploring particular cases. In other words, the extracted phenomena put the EPPMCs in the position where they could capitalize on their mathematical experience and re-act in an investigative manner to impulses that took them out of their comfort zone.

\subsection{Abstracting mathematical phenomena from optimization-inviting tasks}

This trigger emerged from the accounts of three EPPMCs who described their engagement in some common everyday-life tasks. These tasks required making nontrivial decisions that might have been optimized (i.e., leading to more advantageous consequences) if approached with mathematical methods. Let me illustrate such tasks with two accounts from PT and SK.

\section{Account 3: No rainfall drop left behind}

"I lived for several years on a farm that was far away from the city and didn't have an aqueduct. We collected rainwater from the roofs and stored it in tanks. In one particular farm we had four tanks. There were three buildings, each having a tank that could go by gravity to the biggest collecting tank at the lowest level. The constant issue was with moving water between the tanks and emptying them into the collecting tank not to waste the rainfall. Then, the emptiness of the tanks needed to be optimized [i.e., at which point their water should be poured into the collective tank?]".

\section{Account 4: Eating apples to the maximum}

"When we were children, my little brother came to me once with four apples on a plate. I wasn't courteous and took the biggest apple. My brother took the second biggest apple and finished eating it before I finished with my apple. Then, he took the third biggest apple. Only then I paid attention that the last apple was very small and the overall mass of my apples was smaller than the mass of his ones. This was quite annoying because I was the one to choose the first apple, so I could choose differently. Then, a question arose: I had the right to choose first, but the natural choice of the biggest apple was a mistake. Which apple should I have taken to maximize my portion?".

While not all of us are daily concerned with collecting rainwater efficiently and winning apple-eating competitions, EPPMCs described such tasks as a routine at particular points in their lives. Additional examples of optimization-inviting tasks included planning the shortest driving path between multiple destinations, detecting the right key on a bunch in the minimal number of trials, and opening a tap to fill a bathtub in a way that it will take an exact amount of time. When referring to their accounts, the EPPMCs explained the resonance that they experienced in these tasks with the value that they ascribed to finding an optimal solution (like in Account 3) and with the desire to compensate a feeling of disappointment with their initial decisions that they made when coping with the task (like in Account 4).

The mathematical phenomena that the EPPMCs formulated in this trigger were rooted in the original optimization-inviting tasks. Specifically, the tasks pre-determined particular components that needed to be optimized, subject to a variation of other components of the situations that have been brought to the fore. Yet, it is important to highlight that the 
formulated phenomena did not model the tasks since they did not preserve some of their key constraints (see Kaiser, 2005 and Borromeo Ferri, 2006 for an accepted approach to modeling in mathematics education). For instance, PT shared that collecting rainwater "made me think about a general situation where there are $n$ tanks with capacity $c_{1}, c_{2}, \ldots, c_{n}$ and a collecting tank has an infinite capacity." Similarly, SK got interested in "finding a winning strategy in a game where each one of the two players takes a turn and chooses weights from a given set." These are just two examples illustrating a general pattern where EPPMCs' mathematical phenomena constituted abstractions rather than models of their original task.

\subsection{Wishing to pose a problem "here and now"}

This trigger pertains to common situations where an organizing committee of a forthcoming $\mathrm{MC}$ realizes that a problem in a particular content area, and of a specific degree of difficulty, is needed to complete a problem. In the words of KK,

The committee builds a questionnaire from a pool of problems that have been nominated. Sometimes you look at the questionnaire and realize that something is missing in it, some problem. For example, a geometry problem whose difficulty is this and that. And there are no such problems in the pool. Possibly, there are forty more problems there, but none of them fits. So you start thinking where to get such a problem and, maybe it's easier just to sit and invent one yourself.

Whether a member of the committee decides to come up with the problem themselves or whether the committee turns to an external person specializing in the relevant content area (see Section 5.1), the participants were unanimous in their dislike for such impulses making them come up with a problem "here and now". In the words of AC, "The problem needs to come from being interested in something. The worst approach to posing a problem is to wish to pose it."

In the two former triggers, the data were replete with colorful details pointing at how organic the path from a triggering impulse to an eventually posed problem was. However, in this trigger, the EPPMCs generally referred to their experiences of "working hard" and even "suffering". Five participants stated that they do not have the ability to pose problems in these circumstances, and one shared that he does not engage when such requests come from MC committees, "Not because I don't want to give a hand, but because I have spent too many years with Olympiads to know that I simply can't come up with something decent." The low quality of posed problems was highlighted by seven EPPMCs. For instance, AG entitled such problems as "plugs" because "they may elevate the quality of the MC questionnaire by filling the holes in it and making it more balanced. But they usually don't stand alone as a MC problem should."

\section{Discussion}

The contribution of this study to the body of knowledge on mathematical problem posing can be decomposed on two planes: the plane of experienced problem posers who are acknowledged experts in this activity, and the plane of students and teachers who are often novices to problem posing. 


\subsection{Problem-posing expertise}

The reported investigation is one of the first to explore expert problem posing. Spurred by the interest in "where EPPMCs' problems come from," this study investigated problem-posing triggers as they emerged from twenty-six EPPMCs from nine countries. The study resulted in three broad categories of triggers. The first category pertains to situations where the EPPMCs engaged in activities that are replete with potentially triggering mathematical impulses (e.g., problems, concepts, theorems, problem-solving methods). There, the noticing of EPPMCs was often drawn to impulses within the areas of their mathematical specializations. These triggers were described in emotionally-loaded terms that resonated with the feelings of appreciation, surprise, challenge, and innovation. The second trigger captures common everyday-life tasks where an application of mathematical methods could lead to more optimal decisions. The accounts of these situations emphasized the desire to compensate for self-disappointment with an initially-made decision and the value of finding a better alternative. The third trigger attests to instances where a problem with partially predetermined properties was needed for a forthcoming MC, which stimulated the EPPMCs to pose "here and now". There was a consensus among the participants about how difficult it is to pose in such situations and about the low quality of the resulting problems. Some EPPMCs even described their posing experiences within this trigger in terms of "suffering".

From the perspective of Mason (2002), the resonances of the two former triggers may be associated with the EPPMCs experiencing "a sudden sense of heightened awareness and opportunity" to choose "a fresh alternative" and "being open to uncertainty" (p. 70). Indeed, these encounters with novel impulses were described as a welcome disturbance that is capable of changing the objectives that the EPPMCs pursued in the preceding moments. This cannot be said about the third trigger, where a creation of a problem was not a matter of becoming aware of an opportunity but an obligation that needed to be fulfilled.

A complementary explanation for the identified contrast can be offered based on the mathematical phenomena associated with each trigger. Particularly, let me attend to the relation between the mathematical phenomena characteristic to the triggers and the construct of nesting ideas (Kontorovich \& Koichu, 2012, 2016). A phenomenon distilled from the two former triggers could be easily manipulated, for instance through varying or specifying its elements. The unfamiliarity of the phenomenon and its challenge to an EPPMC specializing in the content area, suggests that the future problems are likely to be new and challenging for the solvers. True, on the first encounter with a new mathematical phenomenon, EPPMCs might not have been sure whether, why or how the phenomenon occurs; yet, they could already sense its prospects. Accordingly, it seems not unreasonable to suggest that acting on the two former triggers had the potential to reward the EPPMCs not just with new problems but also with new nesting ideas that would expand their knowledge base. No immediate potential of such an ilk could be associated with the third trigger, which invited constructing problems through manipulations with the familiar (Kontorovich \& Koichu, 2012, 2016 for the value of the feeling of innovation in expert problem posing).

It is also interesting to contrast the findings with the insights that can be discerned from experts' self-reflections. Overall, the study echoes the experts' message that familiar problems, advanced mathematics, and real-life situations could be utilized (by them) for posing new quality problems (Avital \& Libeskind, 1978; Brown \& Walter, 1983; Kilpatrick 1987; Sharigin, 1991; Walter, 1978). However, this is not tantamount to a view that problems can be generated "almost from anything" (Walter, 1978, p. 3). The 
introduced lens of triggers allowed pointing at a special affective bond that can be established between an external impulse and an expert; a bond that spurs them to react mathematically, making the encounter between the two memorable for many years. The centrality of the affective resonance as it emerged in this study and its lack in published self-reflections resonates with Mason's (2002) observation that experts' sensitivity "to notice certain things is integrated into their professional functioning so that all they are aware of is a possibility to act, but not necessarily of the distinctions which trigger that act" (p. 33). That being said, it is important to acknowledge the methodological limitations of this study as well as its modest number of participants who have been involved only in some among many MCs.

\subsection{Resonance with research on students and teachers' problem posing}

The findings of this study resonate with ongoing discussions on promoting problem posing among students and teachers (e.g., Cai et al., 2015; Singer et al., 2013). The two former triggers (see Sections 5.1 and 5.2) bear resemblance to an a-didactical approach (Koichu, in press) since they pertain to instances where the EPPMCs created problems as a result of engaging in activities with problem posing not being among their explicit goals. The third trigger (see Section 5.3) features what may be seen as an EPPMCs' analogue to the didactical approach of free problem-posing situations where a person is asked "to generate a problem from a given, contrived or a naturalistic situation" (Stoyanova, 1998, p. 173). Furthermore, the consensual participants' preference to the two former triggers and their reluctance about the third one align with problem-posing research emphasizing the potential of a-didactical situations (e.g., Crespo \& Sinclair, 2008; English, in press; Koichu, in press; Koichu \& Kontorovich, 2013). Indeed, a key characteristic of these triggers seems to be that the EPPMCs were in the position to decide whether and when to turn problem posing into a self-imposed objective. Furthermore, the richness and the variety of situations in which the EPPMCs chose to pose a problem allows suggesting that this decision is less driven by a special activity or a task in which they were involved but more a matter of a reflection-in-action (cf. Schön, 1983) that is sensitized to opportunities (cf. Mason, 2002). A well-renowned problem poser, Marion Walter, put it as "[...] problem posing becomes second nature after you do it for a while. I seem to look at the world through 'problem' posing' colored glasses" (Walter in Baxter \& Walter, 1978).

Overall, this study allows associating expert-like problem posing with instances where a person becomes disturbed by some external impulse that resonates with their mathematical experiences, where they extract a previously unfamiliar mathematical phenomenon from a disturbing experience, and where they initiate a mathematical investigation of the phenomena while posing problems as part of this investigation. Notably, these behaviors are not foreign to problem-posing research as similar patterns have been reported in several studies on students and teachers (e.g., Cifarelli \& Cai, 2005; Koichu, in press; Koichu \& Kontorovich, 2013). Interestingly, many of these observations were accompanied by researchers' acknowledgement of the quality of the posed problems. These encouraging similarities might be viewed as an evidence that (at least) some novices can experience problem posing in an expert-like manner. Is it worthwhile for novices to experience expert-like problem posing? How can such experiences become 
more common among school students and teachers? These are just some of the questions that future research might pursue.

Another notable similarity between experts and novices pertains to the third trigger, where the participants were reluctant about situations where they needed to come up with problems "here and now". This reluctance echoes with a commonly reported finding on students and teachers not being interested in the problems that they posed as a response to problem-posing tasks (e.g., Crespo \& Sinclair, 2008; Kontorovich et al., 2012). While some might consider this lack of interest as a deficiency that needs to be addressed, this study allows interpreting it as an expert-like re-action to an adverse problem-posing trigger.

Overall, the aforementioned similarities may be just a tip of the iceberg, and it is likely that students and teachers manifest expert-like problem posing more frequently than research assumes, simply because the mathematics education community still has a limited understanding of what expertise in this endeavor looks like. Hopefully, this study will "trigger off' further research on expertise; research that will be useful for supporting students and teachers in coming up with good mathematical problems. In the meantime, if we were to extract some practice-oriented suggestions from this study, it would be not to fetishize problem posing as a means onto itself. Instead, we should give serious thought to promoting problem posing within some a-didactical activity, such as a mathematical investigation or problem solving. To support this process, teachers themselves need to be sensitized to problem-posing opportunities and notice problem-prosing triggers around us.

Acknowledgements I am grateful to Jinfa Cai, Roza Leikin, and anonymous reviewers for their constructive criticism and suggestions, to John Mason for his insights and help with the theoretical framework, and to Boris Koichu for his feedback on the earlier drafts and tremendous contribution to the overarching project. I wish to thank Robert Hartley for proofreading the paper.

Open Access This article is licensed under a Creative Commons Attribution 4.0 International License, which permits use, sharing, adaptation, distribution and reproduction in any medium or format, as long as you give appropriate credit to the original author(s) and the source, provide a link to the Creative Commons licence, and indicate if changes were made. The images or other third party material in this article are included in the article's Creative Commons licence, unless indicated otherwise in a credit line to the material. If material is not included in the article's Creative Commons licence and your intended use is not permitted by statutory regulation or exceeds the permitted use, you will need to obtain permission directly from the copyright holder. To view a copy of this licence, visit http://creativecommons.org/licenses/by/4.0/.

\section{References}

Andžāns, A., Bērziņa, I., \& Bonka, D. (2006). The "Baltic Way" contest. Mathematics Competitions, 19(2), 3141.

Avital, S., \& Libeskind, S. (1978). Some ideas on how to create mathematical problems. International Journal of Mathematics Education in Science and Technology, 9(4), 417-422.

Baxter, J. A., \& Walter, M. (1978). Some reflections on problem posing: A conversation with Marion Walter: Reflect and discuss. Teaching Children Mathematics, 12(3), 122-128.

Borromeo Ferri, R. (2006). Theoretical and empirical differentiations of phases in the modelling process. ZDM, $38(2), 86-95$.

Brousseau, G. (1997). In N. Balacheff, M. Cooper, R. Sutherland, \& V. Warfield (Eds.), Theory of didactical situation in mathematics. Dordrechtm the Netherlands: Kluwer.

Brown, S. I., \& Walter, M. I. (1983). The art of problem posing. Philadelphia, PA: Franklin Institute Press.

Cai, J., \& Hwang, S. (in press). Learning to teach through mathematical problem posing: Theoretical considerations, methodology, and directions for future research. International Journal of Educational Research. 
Cai, J., Hwang, S., Jiang, C., \& Silber, S. (2015). Problem-posing research in mathematics education: Some answered and unanswered questions. In F. M. Singer, N. F. Ellerton, \& J. Cai (Eds.), Mathematical problem posing: From research to effective practice (pp. 3-34). New York, NY: Springer Science+Business Media.

Cifarelli, V., \& Cai, J. (2005). The evolution of mathematical explorations in open ended problem solving situations. The Journal of Mathematical Behavior, 24, 302-324.

Crespo, S., \& Sinclair, N. (2008). What makes a problem mathematically interesting? Inviting prospective teachers to pose better problems. Journal of Mathematics Teacher Education, 11(5), 395-415.

Einstein, A., \& Infeld, L. (1938). The evolution of physics. New York, NY: Simon \& Schuster.

Ellerton, N. F. (1986). Children's made-up mathematics problems: A new perspective on talented mathematicians. Educational Studies in Mathematics, 17(3), 261-271.

English, L. D. (in press). Teaching and learning through mathematical problem posing: Commentary. International Journal of Educational Research.

Glaser, B. G., \& Strauss, A. L. (1967). The discovery of grounded theory. Chicago, IL: Aldine.

Kaiser, G. (2005). Mathematical modelling in school - examples and experiences. In G. Kaiser \& H. -W. Henn (Eds.), Mathematikunterricht im Spannungsfeld von Evaluation und Evolution (pp. 99-108). Hildesheim, Germany: Franzbecker.

Kilpatrick, J. (1987). Problem formulating: Where do good problems come from? In A. H. Schoenfeld (Ed.), Cognitive science and mathematics education (pp. 123-147). Hillsdale, NJ: Lawrence Erlbaum Associates.

Klinshtern, M., Koichu, B., \& Berman, A. (2015). Problem posing: From research to effective practice. In F. M. Singer, N. Ellerton, \& J. Cai (Eds.), What do high school teachers mean by saying "I pose my own problems"? (pp. 449-467). New York, NY: Springer.

Koichu, B. (in press). Problem posing in the context of teaching for advanced problem solving. International Journal of Educational Research.

Koichu, B., \& Andžāns, A. (2009). Mathematical creativity and giftedness in out-of-school activities. In R. Leikin, A. Berman, \& B. Koichu (Eds.), Creativity in mathematics and education of gifted students (pp. 285-308). Rotterdam, the Netherlands: Sense Publishers.

Koichu, B., \& Kontorovich, I. (2013). Dissecting success stories on mathematical problem posing: A case of the billiard task. Educational Studies in Mathematics, 83(1), 71-86.

Kontorovich, I. (2015). Why do experts pose problems for mathematics competitions? In C. Bernack-Schüler, R. Erens, E. Eichler \& T. Leuders (Eds.), Views and Beliefs in Mathematics Education: Results of the 19th MAVI Conference (pp. 171-182). Freiburg, Germany: Springer-Spektrum.

Kontorovich, I., \& Koichu, B. (2012). Feeling of innovation in expert problem posing. Nordic Studies in Mathematics Education, 17(3-4), 199-212.

Kontorovich, I., \& Koichu, B. (2016). A case study of an expert problem poser for mathematics competitions. International Journal of Science and Mathematics Education, 14(1), 81-99.

Kontorovich, I., Koichu, B., Leikin, R., \& Berman, A. (2012). An exploratory framework for handling the complexity of mathematical problem posing in small groups. The Journal of Mathematical Behavior, 31(1), 149-161.

Leikin, R., \& Grossman, D. (2013). Teachers modify geometry problems: From proof to investigation. Educational Studies in Mathematics, 82, 515-531.

Lerman, S. (2019). Theoretical aspects of doing research in mathematics education: An argument for coherence. In G. Kaiser and N. Presmeg (Eds.), Compendium for Early Career Researchers in Mathematics (pp. 309324). Springer Open.

Liljedahl, P. (2009). In the words of the creators. In R. Leikin, A. Berman, \& B. Koichu (Eds.), Creativity in mathematics and education of gifted students (pp. 51-70). Rotterdam, the Netherlands: Sense Publishers.

Lincoln, Y. S., \& Guba, E. G. (1985). Naturalistic inquiry. Beverly Hills, CA: Sage.

Mason, J. (2002). Researching your own practice: The discipline of noticing. London, UK: RoutledgeFalmer.

Mason, J. (2008). Being mathematical with and in front of learners: Attention, awareness, and attitude as sources of differences between teacher educators, teachers and learners. In B. Jaworski \& T. Wood (Eds.), The mathematics teacher educator as a developing professional (pp. 31-56). Rotterdam/Taipei: Sense Publishers.

Schoenfeld, A. (1992). Learning to think mathematically: Problem solving, metacognition, and sense making in mathematics. In D. A. Grows (Ed.), Handbook of research on mathematics teaching and learning (pp. 334 370). New York, NY: Macmillan.

Schön, D. (1983). The reflective practitioner: How professionals think in action. London: Temple Smith.

Sharigin, I. F. (1991). Otkuda berutsia zadachi? [where do problems come from?] part I, Kvant, 8, 42-48; part II, Kvant (vol. 9, pp. 42-49) (in Russian).

Silver, E. A. (2013). Problem-posing research in mathematics education: Looking back, looking around, and looking ahead. Educational Studies in Mathematics, 83(1), 157-162. 
Singer, F. M., Ellerton, N. F., \& Cai, J. (2013). PME-special issue: Problem posing in mathematics teaching and learning: Establishing a framework for research. Educational Studies in Mathematics, 83, 1-162.

Singer, F. M., \& Voica, C. (2013). A problem-solving conceptual framework and its implications in designing problem-posing tasks. Educational Studies in Mathematics, 83(1), 9-26.

Stebbins, R. (2001). Exploratory research in the social sciences. Thousand Oaks, CA: Sage.

Stoyanova, E. (1998). Problem posing in mathematics classrooms. In A. McIntosh \& N. Ellerton (Eds.), Research in mathematics education: A contemporary perspective (pp. 164-185). Edith Cowan University: MASTEC.

Stylianou, D. A. (2002). On the interaction of visualization and analysis - The negotiation of a visual representation in problem solving. The Journal of Mathematical Behavior, 21, 303-317.

van Someren, M. Y., Barnard, Y. F., \& Sandberg, J. A. C. (1994). The think aloud method: A practical guide to modeling cognitive processes. London, UK: Academic Press.

Walter, M. (1978). Generating problems almost from anything, part I. Mathematics Teaching, 120, 3-7; part II, Mathematics Teaching (vol. 121, pp. 2-6).

Wenger, E. C. (1998). Communities of practice: Learning, meaning, and identity. New York, NY: Cambridge University Press.

Wenger, E. C., \& Snyder, W. M. (2000). Communities of practice: The organizational frontier (pp. 139-145). January-February: Harvard Business Review.

Wenger-Trayner, E., \& Wenger-Trayner, B. (2015). Introduction to communities of practice: A brief overview of the concept and its uses. Retrieved on 28 July 2019 from https:/wenger-trayner.com/introduction-tocommunities-of-practice/

Wieschenberg, A. (1990). The birth of Eotvos competition. The College Mathematics Journal, 21(4), $286-293$.

Wilkerson-Jerde, M. H., \& Wilensky, U. J. (2011). How do mathematicians learn math?: Resources and acts for constructing and understanding mathematics. Educational Studies in Mathematics, 78, 21-43.

Publisher's note Springer Nature remains neutral with regard to jurisdictional claims in published maps and institutional affiliations. 